\title{
QUANDO O SENTIDO COTIDIANO SOBRE OS ANÚNCIOS ECOA NO MUNDO ACADÊMICO: OS ANOS 2000 E A ASCENSÃO DA PRODUÇÃO CIENTÍFICA SOBRE A RECEPÇÃO DA PUBLICIDADE
}

\author{
WHEN THE EVERYDAY SENSE ON ADS ECHOES IN THE ACADEMIC \\ WORLD: THE 2000'S AND THE RISE OF SCIENTIFIC RESEARCH ABOUT \\ RECEPTION OF ADVERTISING
}

\author{
CUANDO EL SENTIDO COTIDIANO SOBRE LOS ANUNCIOS HACE ECO \\ EN EL MUNDO ACADÉMICO: LA DÉCADA DE 2000 Y LA ASCENSIÓN DE \\ LA INVESTIGACIÓN CIENTÍFICA SOBRE LA RECEPCIÓN DE LA \\ PUBLICIDAD
}

\author{
Elisa Piedras \\ Doutora, PPG Comunicação e \\ Informação, UFRGS \\ e-mailelisapiedras@gmail.com
}

\begin{abstract}
Resumo
O objetivo desta pesquisa é analisar a contribuição dos estudos de recepção da publicidade produzidos no Brasil nos anos 2000 (especificamente a partir das dissertações e teses desenvolvidas nessa perspectiva). A metodologia se ampara na pesquisa bibliográfica e as categorias de analise transversal dos estudos contemplam seu contexto de produção, abordagem, enfoque dado ao processo de recepção e ao receptor, tema, gênero, meio, publico, enfoque teórico e métodos de pesquisa. Como resultados, apresenta-se o panorama da pesquisa em recepção da publicidade desenvolvida nos anos 2000 e a discussão dos avanços e carências nesse campo cientifico.
\end{abstract}

Palavras-chave: estudos de recepção; publicidade e propaganda; comunicação

\begin{abstract}
The objective of this research is to analyze the contribution of reception studies of advertising produced in Brazil in the 2000s (specifically from dissertations and theses developed in this perspective). The methodology is supported by the literature search and the categories of cross-analysis of studies includes its production context, approach, focus given to the process of reception and receiver, theme, genre, medium, audience, theoretical approach and research methods. As a result, it presents an overview of the research desk of advertising developed in the 2000s and the discussion of advances and shortcomings in this scientific field.
\end{abstract}

Key words: reception studies; advertising; communication. 


\section{Resumen}

El objetivo de esta investigación es analizar la contribución de los estudios de recepción de publicidad producidos en Brasil en la década de 2000 (en concreto de disertaciones y tesis desarrolladas en este punto de vista). La metodología se apoya en la búsqueda de la literatura y las categorías de análisis cruzado de los estudios incluyen su contexto de producción, el enfoque, el enfoque dado al proceso de recepción y receptor, tema, género, medio, audiencia, enfoque teórico y métodos de investigación. Como resultado, se presenta una visión general de la investigación de la recepción de publicidad desarrollada en la década de 2000 y la discusión de los avances y las deficiencias en este campo científico.

Palabras clave: estudios de recepción; publicidad y propaganda; comunicación.

\section{INTRODUÇÃO}

A publicidade é uma forma de comunicação caracterizada pela persuasão. Mobilizada por produtos midiáticos como anúncios e campanhas, seu processo comunicativo é constitutivo de práticas culturais de publicitários e de receptores.

Usualmente identificado como publicidade e propaganda, esse gênero midiático guarda em si uma distinção conceitual. A publicidade se dedica à divulgação de produtos e de serviços, daí sua vinculação estrita com o modo de produção capitalista, o mercado e a cultura de consumo. Por sua vez, a propaganda se ocupa da divulgação de ideias e de pessoas (GOMES, 2003).

A pesquisa sobre comunicação publicitária no Brasil tem uma trajetória incipiente quantitativamente, se comparada a outros objetos de estudo desse campo. Isso fica explícito no levantamento elaborado por Jacks (2001), que identificou a carência de pesquisas sobre o tema na década de 1990, quando as poucas investigações existentes abordavam, predominantemente, a linguagem publicitária. Nos anos 2000, com um significativo incremento da produção acadêmica sobre o tema, houve uma diversificação das abordagens, mas a ênfase nos anúncios e em sua linguagem manteve-se bastante representativa.

Além disso, um traço marcante do conhecimento produzido sobre a publicidade consiste na dicotomia entre dois olhares, um econômico funcional e outro crítico denuncista. Em ambas as perspectivas, parece que o mundo social é unicamente determinado pelas condições criadas pelas atividades publicitárias, desconsiderando-se os outros condicionamentos.

Com base nisso, em 1990 podia-se afirmar o mesmo que disse Williams (1995) ainda nos anos 1960: a pesquisa na área está longe de atender às necessidades sociais e culturais que o momento histórico requer. Mas, certamente, algumas exceções se incluíram nessa regra, 
entre elas os três estudos de recepção publicitária produzidos no Brasil nos anos 1990, cujo legado discute-se inicialmente neste artigo.

Os anos 2000 marcam um salto qualitativo na pesquisa brasileira em publicidade, que enfim parece ecoar no mundo acadêmico a força de sua presença no cotidiano contemporâneo. Restringindo-se à produção científica sobre a recepção publicitária, tem-se agora 21 estudos e um campo em ascensão.

Nesse cenário, o objetivo do artigo é analisar a contribuição dos estudos de recepção da publicidade produzidos no Brasil nos anos 2000 (especificamente a partir das dissertações e teses desenvolvidas nessa perspectiva). A metodologia do trabalho se ampara na pesquisa bibliográfica (STUMPF, 2009) e as categorias de analise transversal dos estudos contemplam seu contexto de produção, abordagem, enfoque dado ao processo de recepção e ao receptor, tema, gênero, meio, publico, enfoque teórico e métodos de pesquisa.

Reconstituir a trajetória desses estudos justifica-se acima de tudo pela oportunidade de se construir um olhar sobre a publicidade que busque superar determinismos e construir uma abordagem processual dessa forma de comunicação persuasiva.

\section{LEGADO DOS ESTUDOS SOBRE RECEPÇÃO DA PUBLICIDADE DOS ANOS 1990}

Na década de 1990, entre as 59 dissertações e teses que abordaram a publicidade no Brasil, três adotaram a perspectiva da recepção. Os trabalhos são os seguintes: Quem tem medo da propaganda? Estudo da reação à propaganda através da manifestação espontânea do consumidor em Jornal de Santos (AUGUSTO, 1993), A orgia dos objetos: Estudo sobre recepção, publicidade e "excluídos" (MATOS, 1995) e Mais do que feijão com arroz: Consumo, publicidade e cultura no meio rural (KESSLER, 1997).

Retomando esses estudos pioneiros dos anos 1990, cabe destacar o legado deixado por eles aos novos trabalhos. Em pesquisa antecedente, identificou-se as abordagens que caracterizam esses estudos de recepção: sociocultural, sociodiscursiva e comportamental (JACKS, MENEZES e PIEDRAS, 2008). As pesquisas dos anos 1990 exploram dois perfis teóricos, um ligado aos debates multidisciplinares dos Estudos Culturais, especialmente latino-americanos, e outro orientado por autores provenientes do campo da Economia e do Marketing, focados no comportamento do consumidor.

Os trabalhos vinculados à primeira perspectiva teórica (MATOS, 1995; KESSLER, 1997) remetem à abordagem sociocultural, e sinalizam que não há uma correspondência 
necessária entre o discurso publicitário e as práticas de consumo. O outro trabalho, ligado à segunda perspectiva teórica (AUGUSTO, 1993), enquadra-se na abordagem comportamental, e revela a ambiguidade da relação da audiência com os meios e discursos publicitários, ao descrever situações em que o consumidor comporta-se como cidadão.

Nos três estudos, vê-se como elemento comum a "negociação" do sentido a partir dos significados propostos pela publicidade aos receptores, entretanto, no comportamental a problematização detém-se na aceitação/rejeição e nos socioculturais, na exploração das desigualdades e diferenças culturais que interferem nesse processo.

Um aspecto interessante nos estudos de abordagem sociocultural é o tratamento da publicidade em uma perspectiva comparativa, confrontando o consumo entre abastados e "excluídos" e entre os mundos urbano e rural. Dessa forma, mesmo que partindo de objetos e de questionamentos diferentes, ambos constatam a contradição latente no fato de que a publicidade é produzida em um meio (para os ricos / mundo urbano) e destinada a outro (os excluídos / o universo rural).

No que tange ao universo empírico, as pesquisas têm como traço comum a observação do receptor e da mensagem. No estudo comportamental, isso acontece através da análise de cartas enviadas pelos consumidores ao jornal, bem como das ocorrências registradas junto aos órgãos de defesa do consumidor. Já nas pesquisas socioculturais, a discussão é composta pela análise de anúncios publicitários veiculados na televisão, observação etnográfica e entrevistas com receptores ("excluídos" ou do meio rural), visando à identificação das mediações do processo.

Destaca-se que, apesar de partirem de premissas particulares, os três estudos apresentam em seus resultados empíricos um receptor que tem um papel ativo no processo comunicativo, resistindo, descartando, reelaborando e apropriando-se da publicidade.

Outro traço em comum é a discussão do tema do consumo em relação à publicidade, identificando-a como mediadora das práticas de consumo, complementada pelo contexto sociocultural dos sujeitos, seja a questão da classe social ou das diferenças entre rural e urbano.

Apesar de alguns limites tais pesquisas apresentam algumas contribuições muito relevantes para a busca do entendimento da relação entre os receptores, a publicidade e o consumo. Como se trata de estudos empíricos, desenvolvidos a partir de estratégias teóricometodológicas que contemplam o universo cultural dos receptores, os dados revelam, mesmo que parcialmente, o fenômeno de maneira concreta, complexa e dinâmica. Os resultados 
trazem, portanto, informações sobre situações e públicos específicos que podem alavancar novas pesquisas, capazes de dar-lhes prosseguimento, superando suas falhas.

\section{PANORAMA DA PESQUISA EM RECEPÇÃO DA PUBLICIDADE DESENVOLVIDA NOS ANOS 2000}

Nos anos 2000, ampliou-se o número de trabalhos que abordam a recepção da publicidade, chegando a 21 . No cenário da pós-graduação brasileira, enquanto o número de dissertações e teses triplicou a quantidade de estudos voltados à recepção publicitária cresceu sete vezes, o que é bastante significativo. Esse fato pode estar relacionado a uma ampliação da percepção dos pesquisadores a respeito da relevância desse tema, que permeia tão fortemente o cotidiano contemporâneo. Do mesmo modo, o aumento do número de programas de PósGraduação em Comunicação no país naturalmente incrementou a produção científica nas temáticas em geral, entre elas a publicidade. Além disso, o legado deixado pelos três estudos de recepção publicitária produzidos nos anos 1990 certamente contribuiu para isso.

Os 21 trabalhos que exploram a publicidade desde a perspectiva da recepção estão distribuídos entre 15 dissertações de mestrado e seis teses de doutorado. Retomando as abordagens pelas quais caracterizou-se os estudos de recepção, nos anos 1990 estes foram predominantemente socioculturais, já nos anos 2000 observou-se um viés majoritário comportamental (11 trabalhos, sendo oito dissertações e três teses). Essa abordagem foi seguida pela sociocultural, com sete estudos (quatro dissertações e três teses), e, por último, pela sociodiscursiva, com três pesquisas (todas dissertações).

Antes de cumprir o objetivo de apresentar os estudos propriamente ditos, cabe destacar alguns aspectos genéricos do contexto da produção científica sobre recepção publicitária no Brasil ao longo dos anos 2000.

Geograficamente concentrada, a origem das pesquisas restringe-se às regiões Sul (especificamente do estado do Rio Grande do Sul, cidades de Porto Alegre e São Leopoldo) e Sudeste (particularmente São Paulo e Rio de Janeiro, cidades de São Paulo e São Bernardo do Campo), sendo que um trabalho, produzido no Centro-Oeste (Distrito Federal, cidade de Brasília), configura a exceção.

São Paulo concentra 11 trabalhos: três produzidos na ESPM; dois, na USP; dois, na UMESP; dois, na UNIP; um, na UNESP; e um, na FCL (Faculdade Cásper Líbero). Nessas universidades, foram realizados sete dos 11 estudos de abordagem comportamental, além de todos os sociodiscursivos (três) e de uma pesquisa de corte sociocultural. Os estudos 
produzidos na ESPM, USP e UMESP adotam tanto abordagem sociodiscursiva quanto comportamental, os da USP possuem um viés sociocultural, enquanto os da UNESP, UNIP e FCL (Faculdade Cásper Líbero) preconizam a abordagem comportamental.

O Rio Grande do Sul concentra seis trabalhos: três realizados na UNISINOS; dois, na PUCRS: e um, na UFRGS. Essas instituições reúnem a produção de quatro dos cinco trabalhos de abordagem sociocultural; um, de abordagem comportamental; e nenhum de sociodiscursiva. As pesquisas produzidas na UNISINOS e UFRGS caracterizam-se por seguir a abordagem sociocultural, exclusivamente, enquanto os trabalhos da PUCRS contemplam tanto a sociocultural quanto a comportamental.

Do Rio de Janeiro, são originários três estudos. Dois deles foram desenvolvidos na UFRJ e um, na UERJ. Nessas instituições, foram produzidas três das 11 pesquisas de abordagem comportamental, nenhuma de abordagem sociodiscursiva ou sociocultural. Os trabalhos realizados na UFRJ e UERJ preconizam a abordagem comportamental. Por fim, no Distrito Federal, a UnB apresenta a produção de um estudo sobre a recepção da publicidade, de abordagem sociodiscursiva.

Voltando-se aos estudos em pauta, cabe agora identificar suas abordagens:

\begin{tabular}{|c|c|c|c|}
\hline & Ano & Título & Autoria \\
\hline \multirow{6}{*}{ 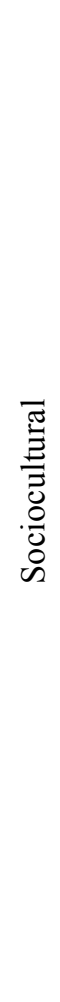 } & 2000 & Os jovens e a recepção da publicidade televisiva & $\begin{array}{l}\text { MALDANER, Nilse } \\
\text { Maria/UMESP }\end{array}$ \\
\hline & 2002 & $\begin{array}{l}\text { Mulher e publicidade: Estudo da produção e da } \\
\text { recepção da identidade da mulher-mãe na mídia } \\
\text { televisiva }\end{array}$ & $\begin{array}{l}\text { SILVA, Denise Teresinha } \\
\text { da/UNISINOS }\end{array}$ \\
\hline & 2003 & $\begin{array}{l}\text { Midia e identidade regional: Negociações da } \\
\text { gauchidade na recepção das propagandas políticas no } \\
\text { RS }\end{array}$ & $\begin{array}{l}\text { GUTBIER, Maria } \\
\text { Suziane/UNISINOS }\end{array}$ \\
\hline & 2004 & $\begin{array}{l}\text { Interações com a comunicação visual urbana: } \\
\text { Pesquisa qualitativa em Porto Alegre e na BR 116, } \\
\text { trecho Porto Alegre - Canoas }\end{array}$ & $\begin{array}{l}\text { ESPINOSA, Lara Regina } \\
\text { Moralles/UNISINOS }\end{array}$ \\
\hline & 2005 & $\begin{array}{l}\text { As representações sociais do receptor infantil de duas } \\
\text { escolas da cidade de São Paulo, a partir de } \\
\text { comerciais de TV }\end{array}$ & YANAZE, Liriam/USP \\
\hline & 2007 & $\begin{array}{l}\text { Publicidade na "Terra do Nunca": As relações entre } \\
\text { consumo, juventude e escolha do curso de Publicidade } \\
\text { e Propaganda }\end{array}$ & $\begin{array}{l}\text { GOELLNER, Rene Luiz } \\
\text { Vilodre/UFRGS }\end{array}$ \\
\hline
\end{tabular}




\begin{tabular}{|c|c|c|c|}
\hline & 2007 & $\begin{array}{l}\text { Publicidade, imaginário e consumo: Anúncios no } \\
\text { cotidiano feminino }\end{array}$ & PIEDRAS, Elisa/PUCRS \\
\hline \multirow{3}{*}{ 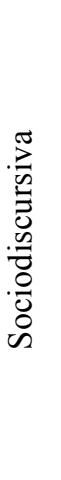 } & 2004 & $\begin{array}{l}\text { Marginal ou invisível? A representação social de } \\
\text { usuários de drogas injetáveis nas publicidades do } \\
\text { Ministério da Saúde }\end{array}$ & $\begin{array}{l}\text { SIQUEIRA, Mauro Henrique de } \\
\text { Miranda / UnB }\end{array}$ \\
\hline & 2008 & $\begin{array}{l}\text { Discurso publicitário como dispositivo disciplinar: Os } \\
\text { impactos da campanha "Real Universitário" na } \\
\text { recepção do público jovem }\end{array}$ & VAZ, Natalia de Alcantara/ ESPM \\
\hline & 2009 & $\begin{array}{l}\text { A recepção pelos paulistanos das mensagens } \\
\text { midiáticas de divulgação do turismo na Bahia }\end{array}$ & $\begin{array}{l}\text { CARVALHO, Maria do Perpétuo } \\
\text { Socorro Magalhães Freire/ ESPM }\end{array}$ \\
\hline \multirow{8}{*}{ 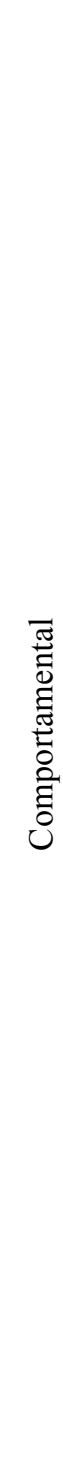 } & 2000 & $\begin{array}{l}\text { A comunicação mercadológica trabalhando a } \\
\text { motivação no consumo infantil }\end{array}$ & MARIN, Sergio Sanches/ UMESP \\
\hline & 2000 & $\begin{array}{l}\text { Uroboros: Globalização, publicidade e Oliviero } \\
\text { Toscani }\end{array}$ & $\begin{array}{l}\text { CAVALCANTI, Leonardo } \\
\text { Schlesinger / UFRJ }\end{array}$ \\
\hline & 2001 & $\begin{array}{l}\text { A propaganda institucional como formadora de } \\
\text { atitude }\end{array}$ & AZEVEDO, Suzana / PUCRS \\
\hline & 2003 & $\begin{array}{l}\text { Mídia e alcoolismo: A ascendência da televisão no } \\
\text { consumo de álcool pelos adolescentes }\end{array}$ & $\begin{array}{l}\text { MILAGRES, Christiane Reis/ } \\
\text { UFRJ }\end{array}$ \\
\hline & 2004 & $\begin{array}{l}\text { Ética na propaganda sob o olhar do consumidor e } \\
\text { suas significações: Um estudo a partir de denúncias } \\
\text { encaminhadas ao CONAR }\end{array}$ & $\begin{array}{l}\text { BRAGAGLIA, Ana Paula/ } \\
\text { UERJ }\end{array}$ \\
\hline & 2006 & $\begin{array}{l}\text { Mudança de atitude: Resistência e comunicação } \\
\text { persuasiva }\end{array}$ & BARROS, José Carlos de/ USP \\
\hline & 2007 & $\begin{array}{l}\text { A comunicação das campanhas sociais na televisão: A } \\
\text { leitura do jovem sobre o referendo da comercialização } \\
\text { de armas de fogo e munição no Brasil }\end{array}$ & $\begin{array}{l}\text { PAIXÃO, Tatiane Oliveira / } \\
\text { UNESP }\end{array}$ \\
\hline & 2008 & $\begin{array}{l}\text { Comunicação publicitária criativa: Um estudo da } \\
\text { recepção sobre a peça } A \text { Semana feita para a revista } \\
\text { Época }\end{array}$ & PATARA, Luciana/ UNIP \\
\hline
\end{tabular}




\begin{tabular}{|l|l|l|l|}
\hline 2008 & $\begin{array}{l}\text { Jingle - informação e entretenimento: A recepção dos } \\
\text { jingles pelos ouvintes da Gazeta FM }\end{array}$ & CAMPOS, Roseli Trevisan/ FCL \\
\hline 2008 & $\begin{array}{l}\text { O estímulo audiovisual na comunicação publicitária } \\
\text { da marca Havaianas: Um estudo da recepção a partir } \\
\text { da diferenciação dos gêneros }\end{array}$ & $\begin{array}{l}\text { VINIC, Richard / UNIP } \\
\text { Limites do público privado na paisagem midiática - } \\
\text { televisão pública: Cidadania e consumo }\end{array}$ & $\begin{array}{l}\text { CURY, Maria Cecília Andrelucci/ } \\
\text { ESPM }\end{array}$ \\
\hline
\end{tabular}

Diante desse panorama, pode-se observar detalhadamente os caminhos teóricos, metodológicos e empíricos percorridos nos estudos recentes.

O processo de recepção é entendido, na maioria desses estudos, como práticas complexas de construção do sentido, que transcendem o contato com os meios e confundemse com a vida cotidiana. Essas práticas são permeadas pelas mediações, onde se estabelece um processo de interação e negociação entre anunciantes e consumidores, relativizando o poder de influência da publicidade. Compreender isso permite situar a recepção como instância do processo comunicacional, em que o sentido se constrói em negociações entre discursos e identidades. Destaca-se que, apesar de compreender teoricamente a recepção como um processo pautado por aspectos socioculturais, empiricamente a maioria dos estudos se enquadra em uma abordagem comportamental, privilegiando condicionamentos individuais e psicológicos como efeitos e influências.

O receptor geralmente é visto nesses trabalhos como sujeito ativo no processo de comunicação, pois, apesar de pressionado pelas estratégias dos produtores, ele é constituído por práticas de natureza cultural que permitem negociar a comunicação segundo valores, ideias, atitudes, traços culturais, que competem com o que é veiculado pela publicidade. Do mesmo modo, o receptor opõe resistência, de maneira consciente ou inconsciente, em função de sua sensibilidade, ideologia, atitude diante da vida e diante do meio ou da mensagem em particular, e é de acordo com esse universo, que o receptor dá sentido às imagens que lhe chegam de forma desordenada.

O tema predominante nos 21 estudos sobre recepção da publicidade, nas três abordagens, é o consumo, presente em sete pesquisas (com variações para consumo juvenil, consumo e cidadania e comportamento do consumidor). A publicidade em si (dois trabalhos comportamentais) e o imaginário (dois trabalhos), além de identidade regional, identidade 
feminina e violência (um estudo sobre cada tema), também são colocados em questão, explicitando o quão multifacetada é a articulação que a publicidade estabelece com o mundo social.

De fato, mesmo quando não está explicitamente indicado, o consumo é um tema bastante articulado à publicidade. Mesmo considerando-a desde uma perspectiva processual e sociocultural, cabe lembrar que seu objetivo primeiro é a persuasão em favor do consumo de determinados produtos, ideias e marcas.

É interessante e relevante observar que, nos anos 2000, muitos trabalhos se empenhem em explorar as sutilezas da relação publicidade-consumo e dos papéis de receptor e consumidor. Em função disso, a própria recepção ainda foi, por vezes, tratada como algo que ocorre como "efeito" da publicidade (dois trabalhos sociodiscursivos) ou sofra sua "influência" (um estudo comportamental). Entretanto, cabe destacar que, apesar de sua vinculação com o consumo, a comunicação publicitária constitui um produto midiático e cultural cuja recepção envolve uma riqueza de aspectos que vão muito além da persuasão por uma estratégia comercial, o que é revelado por algumas dessas pesquisas.

Quanto aos gêneros abordados nos trabalhos, a publicidade (12 pesquisas) foi seguida da publicidade e propaganda (cinco) e, por fim, estudos sobre propaganda (quatro), seja eleitoral ou governamental. Retomando a distinção conceitual entre a publicidade e a propaganda, observa-se que a comunicação persuasiva de cunho comercial destinada à divulgação de bens de consumo concentra o interesse da maioria das pesquisas. Isso acompanha a realidade da produção e difusão do conhecimento sobre o tema nas universidades brasileiras, onde esses aspectos são privilegiados, refletindo uma realidade do mercado. Entretanto, as pesquisas que estudam a propaganda ideológica são precursoras em colocar em pauta no Brasil questões relevantes como a comunicação persuasiva de interesse público, que visa a algo bem mais legítimo ética e moralmente do que o lucro privado das instituições anunciantes.

Entre os suportes publicitários eleitos pelos pesquisadores, a televisão predomina (11 trabalhos, sete comportamentais, um sociodiscursivo e três socioculturais), seguida pelo rádio (um), revista (um), cartazes e folhetos (um), mídia externa (um) ou mídia em geral (um). Algumas pesquisas (quatro) optaram por não abordar a publicidade em nenhum meio específico. Nesse aspecto, os estudos refletem a proeminência da associação da publicidade com os meios audiovisuais, que de fato observa-se empiricamente quando um receptor se remete a um anúncio, narrando "uma propaganda da televisão". Por outro lado, ao eximir-se de eleger um meio como plataforma publicitária para observar sua recepção, uma parte dos 
estudos se alinha à perspectiva da publicidade como um fluxo de anúncios, cuja natureza se dá na apropriação que o receptor faz das ofertas estrategicamente expostas pelo publicitário.

Do mesmo modo, poucos veículos foram selecionados pelos pesquisadores como objetos empíricos, sendo a revista Veja e rádio Gazeta FM 2 exceções entre os 21 trabalhos. $\mathrm{Na}$ televisão são estudados anúncios diversificados, sem representatividade limitada a nenhuma abordagem, sendo eles de marcas (Real, Benetton, Havaianas), de categorias de produto (refrigerante), relativos a uma data promocional (Dia das Mães) ou a campanhas governamentais (prevenção ao uso de drogas, de tabaco, referendo sobre comercialização de armas). Cabe discutir essa opção metodológica, pois, ao recortar um tema para pautar o estudo, muitos investigadores recortam também a experiência de recepção dos seus informantes, o que distancia a pesquisa da realidade empírica.

Quanto aos públicos cuja recepção publicitária foi observada, o recorte predominante segue variação de faixa etária, com ênfase ao público jovem (oito trabalhos, cinco comportamentais, dois socioculturais e um sociodiscursivo), seguido de adultos (quatro pesquisas), além de crianças e mulheres (dois estudos cada), sem representatividade de nenhuma abordagem. Não deixa de ser curioso que, entre outras importantes variáveis que condicionam a recepção publicitária, como a classe social ou o gênero, por exemplo, o aspecto geracional seja privilegiado pela maioria dos trabalhos. Talvez isso possa estar ligado aos processos psicográficos de segmentação de público-alvo recorrentes no mercado publicitário, o que merece ser questionado, já que se distancia fortemente dos fundamentos teóricos adotados nesses estudos acadêmicos.

Tratando-se dos enfoques teóricos, os Estudos Culturais constituem a principal referência, especialmente nas abordagens sociocultural e sociodiscursiva. Esses adotam a teoria das mediações (Martín-Barbero) e o modelo das multimediações (Guillermo Orozco), recorrendo ainda a autores como Canclini e Hall. Suas ideias são complementadas por autores de orientação culturológica francesa como Bourdieu, Foucault, Baudrillard e Maffesoli. Sunkel, Campbell e Charaudeau fundamentam alguns trabalhos sociodiscursivos. Diversos nomes como Freud, Piaget, Eco, Ferrés, Wolton, Kotler, Jakobson, Berlo, Schiffman e Lazar são citados nos estudos comportamentais.

A diversidade de autores e linhas de pensamento que, algumas vezes, é encontrada em um só trabalho não deixa de ser impactante. Entretanto, isso revela como a flexibilidade e a abertura ao diálogo propostas pelos Estudos Culturais se concretizam nesses estudos. Algo que merece destaque, entretanto, é a escassa presença de autores que se dedicam a investigar especificamente a publicidade, não necessariamente desde a perspectiva da recepção. Isso 
certamente impede muitas pesquisas de fundamentar teoricamente importantes aspectos desse gênero comunicativo, que contribuiriam muito para qualificar a observação empírica do fenômeno.

Quanto aos métodos e às técnicas de pesquisa adotados, é predominante o viés qualitativo (14 trabalhos, proporcionalmente distribuídos entre as abordagens), seguido daquele que mescla quanti-qualitativo (cinco estudos, de todas as abordagens), restando apenas um trabalho quantitativo (comportamental). Essa opção pelo qualitativo guarda coerência com importantes premissas dos estudos de recepção, o que merece ser destacado como aspecto positivo. No entanto, os trabalhos nem sempre alcançam a profundidade, a diversidade e a qualidade de informação esperadas de uma pesquisa desse tipo.

A entrevista e o grupo de discussão (ambos em 11 dos 21 trabalhos) são as técnicas de coleta de dados mais utilizadas, seguidas pelo questionário (nove estudos). Tanto a etnografia quanto o formulário foram utilizados em apenas uma pesquisa cada um. Tais técnicas observacionais são empregadas em todas as abordagens, novamente guardando coerência com os estudos de recepção e a inevitável opção de privilegiar o receptor como fonte de dados. Destaca-se o interesse proporcional em buscar informações a partir de narrativas tanto individuais quanto coletivas, além da ausência de abordagens observacionais inspiradas na etnografia, também preconizadas pelos estudos de recepção.

Além dessas técnicas, algumas pesquisas optaram por outras de viés textual, como a análise de discurso (duas), a análise de conteúdo (uma) e análise de cartas e e-mails (uma), que foram usadas somente nas abordagens sociodiscursiva e comportamental (nenhuma na sociocultural). Nesses casos, especialmente quando as técnicas documentais complementam aquelas observacionais, alguns trabalhos alcançam um importante objetivo dos estudos de recepção, que é contrapor a mensagem do produto midiático à interpretação do receptor.

Dos 21 trabalhos, 13 aplicam duas ou três técnicas (sendo o questionário ou a entrevista uma delas), e oito usam apenas uma técnica. Isso revela a saudável busca de uma complexidade metodológica capaz de dar conta do fenômeno de forma dinâmica e processual, o que é essencial em estudos de recepção, especialmente de um objeto multifacetado e multimidiático como a publicidade.

Através desse panorama, observam-se traços marcantes, recorrentes nos trabalhos, que são o privilégio do viés qualitativo e das técnicas de pesquisa observacional, a busca de dados junto a públicos definidos por faixa etária (especialmente os jovens), explorando sua relação com a publicidade na televisão, articulada à questão do consumo. Mas, além disso, o que se impõe como característica da pesquisa em recepção publicitária nos anos 2000 é o predomínio 
da abordagem comportamental, que paradoxalmente é colocada em prática investigativa através dos fundamentos dos Estudos Culturais, o que aponta importantes demandas para os trabalhos futuros.

\section{RESULTADOS, AVANÇOS E CARÊNCIAS DA PESQUISA SOBRE RECEPÇÃO DA PUBLICIDADE}

Diante do exposto, cabe destacar as contribuições desses trabalhos para a compreensão da complexidade e da dinâmica das relações entre receptores, publicidade e consumo.

Um dos principais avanços da pesquisa sobre a recepção publicitária nos anos 2000 remete a aspectos quantitativos. O crescimento (sete vezes) diante da produção dos anos 1990 situa a publicidade como tema em ascensão nessa perspectiva, já que tal incremento não foi observado nos estudos de recepção como um todo. Esses registram uma redução quando se faz uma relação entre o número de trabalhos e o número de programas de Pós-Graduação (11 nos anos 1990 e 44 atualmente).

Paralelamente a essa questão quantitativa, qualitativamente também houve avanços. Além de explorar apenas os aspectos mercadológicos, ideológicos e persuasivos da publicidade, os estudos abordam objetos empíricos que dão conta de questões que remetem à sociedade e aos seus cidadãos (CURY, 2009). Temas como a ética, o direito do consumidor e as políticas de representação são colocados em pauta (BRAGAGLIA, 2004), além da análise da propaganda eleitoral articulada à identidade regional (GUTBIER, 2003). O papel da publicidade na mediação de consumo de produtos com alto potencial de dano como álcool, tabaco, drogas e armas de fogo também é significativamente investigado (MILAGRES, 2003; SIQUEIRA, 2004; BARROS, 2006; PAIXÃO, 2007).

Apesar de a maioria dos trabalhos privilegiar a abordagem comportamental, buscando efeitos e influências, sua fundamentação teórica remete a outro enfoque, mais interessado no universo sociocultural dos receptores. Nessa perspectiva, há tentativas de comparar os sentidos atribuídos pelos receptores à mensagem publicitária ao significado pretendido pelos publicitários (MALDANER, 2000). O avanço está na relação entre o âmbito da produção e o da recepção, procedimento raro que, em geral, não ultrapassa a análise da mensagem para relacioná-la com a interpretação do receptor.

Outra perspectiva que se abre nos anos 2000 decorre da introdução dos estudos de gênero, problematizando a representação do feminino no âmbito da comunicação publicitária e suas repercussões na recepção e no consumo (SILVA, 2002; VINIC, 2008). 
As relações entre publicidade e consumo mantêm-se em pauta, sendo enfocadas por algumas pesquisas (GOELLNER, 2007). Especificamente, a articulação das práticas de consumo e de recepção da publicidade é discutida no sentido de observar suas intersecções permeadas por hábitos de consumo dos meios, usos da publicidade e competências de leitura (PIEDRAS, 2007).

Outra novidade em relação à década anterior é o predomínio dos jovens como público estudado, o que aparentemente é uma coincidência, já que as pesquisas não explicitam justificativas para a escolha. O meio mais investigado, entretanto, não apresenta inovação, pois permanece sendo a televisão.

Ao passo que surgem os avanços, repetem-se algumas carências observadas nos trabalhos dos anos 1990, tomando uma visão geral dos estudos, que contempla exceções. A estruturação da pesquisa é uma questão que apresenta limites, pois nem sempre os problemas são explicitados e, frequentemente, os objetivos não são amparados pelo quadro teórico. Esse, por vezes, é inadequado para contemplar os objetivos, visto que alguns estudos empregam um referencial de orientação funcionalista para realizar uma pesquisa de caráter qualitativo, ou vice-versa.

Ainda no terreno teórico, não há avanços consideráveis quanto aos autores consagrados no campo (Martín-Barbero, García Canclini e Orozco Gómez), mas sim na incorporação de outros teóricos ligados à especificidade do objeto. Entretanto, não há adoção efetiva de autores brasileiros, mesmo com uma ampla produção em estudos de recepção.

Uma carência recorrente é a falta de clareza metodológica nos trabalhos, seja na adequação entre abordagens, métodos e técnicas, ou apresentação dos procedimentos de coleta, descrição e análise de dados. Isso revela uma falta de consciência em relação ao fato de que, tratando-se de metodologia, a pesquisa é um processo de escolhas, e essas devem ser justificadas.

Outro limite recorrente nos estudos de recepção publicitária produzidos nos anos 2000 é a ausência de articulação entre os conceitos teóricos e a análise dos dados empíricos, o que permite questionar a adequação daquelas noções e seus autores para a interpretação da realidade concreta observada.

Indo adiante, ao buscar perspectivas futuras para esse campo, identificam-se nesse corpus alguns estudos da recepção da publicidade na internet. Diferente de outros cenários, como o do jornalismo, em que se proliferam pesquisas sobre essa plataforma, na publicidade isso ocorre de modo lento e ainda pouco expressivo. Apenas quatro dissertações e uma tese dedicam-se a ela, e esses trabalhos possuem lacunas teórico-metodológicas, especialmente por 
não articularem questões resolvidas tanto nos estudos de recepção quanto nos de cibercultura. Nesse sentido, enfrentar os processos de interação, na internet ou fora dela, é essencial, tendo em vista que no processo de convergência midiática, onde a publicidade é elemento central, todos os meios e gêneros estão se adequando a sua lógica.

Articulada a essa demanda tecnológica, a necessidade de trabalhos que abordem o público infantil se impõe às pesquisas sobre a recepção publicitária. Afinal, ainda que o Brasil esteja em processo de envelhecimento, uma significativa parcela de crianças e jovens que nasceram na era das novas tecnologias coloca em pauta o estudo da relação entre sua formação sociocultural, identidades e visões de mundo decorrentes desse processo de mediação e midiatização (BRAGA, 2006).

Além disso, segundo as pesquisas sobre internet e redes sociais (RECUERO, 2009), o perfil dos usuários dessas é definido majoritariamente por jovens, que privilegiam o computador ao invés da televisão, estabelecendo novas relações com os meios, cuja lógica não é mais de "um para vários", mas de "muitos para muitos". Isso propicia novas formas de apropriação e circulação do conteúdo publicitário, relação ainda pouco estudada neste início de novo milênio. A publicidade na internet se coloca, obviamente, como uma importante temática a ser investigada pela perspectiva da recepção.

Feitas essas observações, cabe destacar que os trabalhos explorados nessa pesquisa contribuem para a compreensão da publicidade, pois seus dados permitem ampliar a visão sobre ela e observar concretamente essa relação dinâmica entre receptores, anúncios e publicitários.

As escolhas teóricas e metodológicas que orientam as pesquisas claramente tentam aproximar-se das premissas dos estudos de recepção, em um movimento que, entretanto, nem sempre é bem-sucedido. Isso é natural em um campo de produção tão incipiente, e precisa ser tomado como demanda já que se trata também de um campo em ascensão.

Apesar de alguns estudos ainda carecerem de conceitos e metodologias que permitam avançar significativamente o entendimento desse importante fenômeno do mundo contemporâneo, muitos passos são dados no sentido de vislumbrar a complexidade do processo de comunicação publicitária.

\section{REFERÊNCIAS}

AUGUSTO, C. Quem tem medo da propaganda? Estudo da reação à propaganda através da manifestação espontânea do consumidor em Jornal de Santos. São Paulo: USP, 1993. Tese (Doutorado em Ciências da Comunicação), Universidade de São Paulo, 1993. 
AZEVEDO, Suzana. A propaganda institucional como formadora de atitude. Porto Alegre: PUCRS, 2001. Dissertação (Mestrado em Comunicação Social), Pontifícia Universidade Católica do Rio Grande do Sul, 2001.

BARROS, José Carlos de. Mudança de atitude: Resistência e comunicação persuasiva. São Paulo: USP, 2006. Tese (Doutorado em Ciências da Comunicação), Universidade de São Paulo, 2006.

BRAGA, José Luiz. A sociedade enfrenta sua mídia: Dispositivos sociais de crítica midiática. São Paulo: Paulus, 2006.

BRAGAGLIA, Ana Paula. Ética na propaganda sob o olhar do consumidor e suas significações: Um estudo a partir de denúncias encaminhadas ao CONAR. Rio de Janeiro: UERJ, 2004. Dissertação (Mestrado em Comunicação), Universidade do Estado do Rio de Janeiro, 2004.

CAMPOS, Roseli Trevisan. Jingle - informação e entretenimento: A recepção dos jingles pelos ouvintes da Gazeta FM. São Paulo: FCL, 2008. Dissertação (Mestrado em Comunicação), Faculdade Casper Líbero, 2008.

CAVALCANTI, Leonardo Schlesinger. Uroboros: Globalização, publicidade e Oliviero Toscani. Rio de Janeiro: UFRJ, 2000. Dissertação (Mestrado em Comunicação), Universidade Federal do Rio de Janeiro, 2000.

CARVALHO, Maria do Perpétuo Socorro Magalhães Freire. A recepção pelos paulistanos das mensagens midiáticas de divulgação do turismo na Bahia. São Paulo: ESPM, 2009. Dissertação (Mestrado em Comunicação e Práticas de Consumo), Escola Superior de Propaganda e Marketing, 2009.

CURY, Maria Cecília Andrelucci. Limites do público privado na paisagem midiáticatelevisão pública: Cidadania e consumo. São Paulo: ESPM, 2009. Dissertação (Mestrado em Comunicação e Práticas de Consumo), Escola Superior de Propaganda e Marketing, 2009.

ESCOSTEGUY, Ana Carolina. Notas para um estado da arte sobre os estudos brasileiros de recepção nos anos 90. In: MACHADO, J.; LEMOS, A.; SÁ, S. (Orgs.) Mídia.Br Porto Alegre: Sulina, 2004.

ESPINOSA, Lara Regina Moralles. Interações com a comunicação visual urbana: Pesquisa qualitativa em Porto Alegre e na BR 116, trecho Porto Alegre-Canoas. São Leopoldo: UNISINOS, 2004. Tese (Doutorado em Ciências da Comunicação), Universidade do Vale do Rio dos Sinos, 2004.

GOELLNER, Rene Luiz Vilodre. Publicidade na "Terra do Nunca": As relações entre consumo, juventude e escolha do curso de Publicidade e Propaganda. Porto Alegre: UFRGS, 2007. Tese (Doutorado em Comunicação e Informação), Universidade Federal do Rio Grande do Sul, 2007.

GOMES, Neusa. Publicidade - comunicação persuasiva. Porto Alegre: Sulina, 2003. 
GUTBIER, Maria Suziane. Mídia e identidade regional: Negociações da gauchidade na recepção das propagandas políticas no RS. São Leopoldo: UNISINOS, 2003. Dissertação (Mestrado em Ciências da Comunicação), Universidade do Vale do Rio dos Sinos, 2003.

JACKS, Nilda. A publicidade vista pela academia: Tendências dos anos 90. In: RAMOS, Roberto (Org.). Mídia, textos e contextos. Porto Alegre: PUCRS, 2001, p. 205-19.

JACKS, Nilda; MENEZES, Daiane; PIEDRAS, Elisa R. Meios e audiências: A emergência dos estudos de recepção no Brasil. Porto Alegre: Sulina, 2008.

JACKS, Nilda; PIEDRAS, Elisa R. A recepção da publicidade: Um campo incipiente (análise de pesquisas produzidas entre 1990 e 2009). In: TRINDADE, Eneus; PEREZ, Clotilde (Orgs.). Há momentos em que precisamos parar: Parar para pensar e discutir os rumos da publicidade e propaganda na contemporaneidade. São Paulo: Schoba, 2010, p. 42-56.

JACKS, Nilda et al. A publicidade "vista" entre 2000 e 2005: Pesquisas com foco na recepção. Eco-Pós. Rio de Janeiro, v. 13, n. 1, p. 14-28, jan./abr. 2010. Disponível em: http://www.pos.eco.ufrj.br/ojs-2.2.2/index.php?journal=revista\&page=article\&op=view\&path $\% 5 \mathrm{~B} \% 5 \mathrm{D}=323$

KESSLER, Janea. Mais do que feijão com arroz: Consumo, publicidade e cultura no meio rural. São Bernardo do Campo: UMESP, 1997. Dissertação (Mestrado em Comunicação Social), Universidade Metodista de São Paulo, 1997.

MALDANER, Nilse Maria. Os jovens e a recepção da publicidade televisiva. São Bernardo do Campo: UMESP, 2000. Dissertação (Mestrado em Comunicação Social), Universidade Metodista de São Paulo, 2000.

MARIN, Sergio Sanches. A comunicação mercadológica trabalhando a motivação no consumo infantil. São Bernardo do Campo: UMESP, 2000. Tese (Doutorado em Comunicação Social), Universidade Metodista de São Paulo, 2000.

MATOS, Rita. A orgia dos objetos: Estudo sobre recepção, publicidade e "excluídos". Salvador: UFBA, 1995. Dissertação (Mestrado em Comunicação e Cultura Contemporânea), Universidade Federal da Bahia, 1995.

MILAGRES, Christiane Reis. Mídia e alcoolismo: A ascendência da televisão no consumo de álcool pelos adolescentes. Rio de Janeiro: UFRJ, 2003. Dissertação (Mestrado em Comunicação), Universidade Federal do Rio de Janeiro, 2003.

PAIXÃO, Tatiane Oliveira. A comunicação das campanhas sociais na televisão: A leitura do jovem sobre o referendo da comercialização de armas de fogo e munição no Brasil. Bauru: UNESP, 2007. Dissertação (Mestrado em Comunicação), Universidade Estadual Paulista Júlio Mesquita Filho, 2007.

PATARA, Luciana. Comunicação publicitária criativa: Um estudo da recepção sobre a peça A Semana feita para a revista Época. São Paulo: UNIP, 2008. Dissertação (Mestrado em Comunicação), Universidade Paulista, 2008. 
PIEDRAS, Elisa. Publicidade, imaginário e consumo: Anúncios no cotidiano feminino. Porto Alegre: PUCRS, 2007. Tese (Doutorado em Comunicação e Informação), Pontifícia Universidade Católica do Rio Grande do Sul, 2007.

PIEDRAS, Elisa Reinhardt. Fluxo publicitário: Anúncios, produtores e receptores. Porto Alegre: Sulina, 2009.

RECUERO, Raquel. Redes sociais na internet. Porto Alegre: Sulina, 2009.

SILVA, Denise Teresinha da. Mulher e publicidade: Estudo da produção e da recepção da identidade da mulher-mãe na mídia televisiva. São Leopoldo: UNISINOS, 2002. Dissertação (Mestrado em Ciências da Comunicação), Universidade do Vale do Rio dos Sinos, 2002.

SIQUEIRA, Mauro Henrique de Miranda. Marginal ou invisível? A representação social de usuários de drogas injetáveis nas publicidades do Ministério da Saúde. Brasília: UnB, 2004. Dissertação (Mestrado em Ciências da Informação), Universidade de Brasília, 2004.

STUMPF, Ida R. C. Pesquisa bibliográfica. In: DUARTE, Jorge; BARROS, Antonio (orgs.). Métodos e técnicas de pesquisa em comunicação. São Paulo: Atlas, 2009.

VAZ, Natalia de Alcantara. Discurso publicitário como dispositivo disciplinar: Os impactos da campanha "Real Universitário" na recepção do público jovem. São Paulo: ESPM, 2008. Dissertação (Mestrado em Comunicação e Práticas de Consumo), Escola Superior de Propaganda e Marketing, 2008.

VINIC, Richard. O estímulo audiovisual na comunicação publicitária da marca Havaianas: Um estudo da recepção a partir da diferenciação dos gêneros. São Paulo: UNIP, 2008.

Dissertação (Mestrado em Comunicação), Universidade Paulista, 2008.

WILLIAMS, Raymond. Advertising: the magic system. In: DURING, Simon (Org.). The Culture Studies Reade. London: Routledge, 1995, p. 320-36.

YANAZE, Liriam. As representações sociais do receptor infantil de duas escolas da cidade de São Paulo, a partir de comerciais de TV. São Paulo: USP, 2005. Tese (Doutorado em Ciências da Comunicação), Universidade Estadual de São Paulo, 2005.

Original recebido em: 20/03/2014

Aceito para publicação em: 15/07/2014

Resumo sobre o autor Elisa Piedras

Graduada em Publicidade e Propaganda e Design Grafico, Mestre em Comunicação e Informação (UFRGS), Doutora em Comunicação Social (PUCRS). Professora do Programa de Pós-Graduação em Comunicação e Informação, Universidade Federal do Rio Grande do Sul. 